\title{
BMJ open Breast cancer survival and season of surgery: an ecological open cohort study
}

\author{
Dorthe Teilum, ${ }^{1}$ Karsten D Bjerre, ${ }^{2}$ Anne M Tjønneland, ${ }^{3}$ Niels Kroman ${ }^{1}$
}

To cite: Teilum D, Bjerre KD, Tjønneland AM, et al. Breast cancer survival and season of surgery: an ecological open cohort study. BMJ Open 2012;2:e000358. doi:10. 1136/bmjopen-2011-000358

- Prepublication history for this paper is available online. To view these files please visit the journal online (http:// bmjopen.bmj.com).

We will be pleased to share the necessary data for the statistical review of our paper. However, it is not possible for us to make the entire data material public available.

Received 30 September 2011 Accepted 1 December 2011

This final article is available for use under the terms of the Creative Commons Attribution Non-Commercial 2.0 Licence; see http://bmjopen.bmj.com

${ }^{1}$ Brystkirurgisk Klinik PBB, Copenhagen, Denmark ${ }^{2}$ Danish Breast Cancer Cooperative Group, Copenhagen, Denmark ${ }^{3}$ Danish Cancer Society, Institute of Cancer Epidemiology, Copenhagen, Denmark

Correspondence to Dr Dorthe Teilum; dorthe.teilum@rh.regionh.dk

\section{ABSTRACT}

Background: Vitamin $D$ has been suggested to influence the incidence and prognosis of breast cancer, and studies have found better overall survival (OS) after diagnosis for breast cancer in summer-autumn, where the vitamin $D$ level are expected to be highest. Objective: To compare the prognostic outcome for early breast cancer patients operated at different seasons of the year.

Design: Open population-based cohort study.

Setting: Danish women operated 1978-2010.

Cases: 79658 adjusted for age at surgery, period of surgery, tumour size, axillary lymph node status and hormone receptor status.

Statistical analysis: The association between OS and season of surgery was analysed by Cox proportional hazards regression models, at survival periods $0-1$, $0-2,0-5$ and $0-10$ years after surgery. A two-sided $p$ value $<0.05$ was considered statistical significant.

Results: Only after adjustment for prognostic factors that may be influenced by vitamin D, 1-year survival was close to significantly associated season of surgery. 2, 5 and 10 years after surgery, the association between $\mathrm{OS}$ and season of surgery was not significant.

Limitations: Season is a surrogate measure of vitamin D.

Conclusions: The authors found no evidence of a seasonal variation in the survival after surgery for early breast cancer. Lack of seasonal variation in this study does not necessarily mean that vitamin $D$ is of no importance for the outcome for breast cancer patients.

\section{INTRODUCTION}

Over the past decades, ecological studies have inspired to the hypothesis that exposure to sunlight and hence difference in serum vitamin $\mathrm{D}$ may influence both risk and prognosis for breast cancer. ${ }^{12}$ The hypothesis has been supported by several in vitro and animal studies, ${ }^{34}$ in addition to case-control and cohort studies with measurements of vitamin $\mathrm{D}$ as serum 25 hydroxy-vitamin $\mathrm{D}$ (25 $(\mathrm{OH}) \mathrm{D}),^{5-15}$ although not all studies including two meta-analyses could support these findings. ${ }^{16-19}$ Four studies found the prognosis of breast cancer to vary with the

\section{ARTICLE SUMMARY}

Article focus

- Breast cancer survival and season of surgery.

Key message

- No evidence of a seasonal variation.

Strengths and limitations of this study

- The sample size (approximately 80000 cases).

- The population-based approach in a limited geographic area.

- The prospectively collected characteristics of tumour and lymph node status.

- The long follow-up (median 10.0 years).

- The lack of information about vitamin D status in the individual patient at the time of surgery.

- It is not known whether vitamin D levels of the breast cancer patients follow that of the background population.

season for diagnosis. The three of them found that patients diagnosed in summer-autumn had a better disease outcome than those diagnosed in winterspring, ${ }^{20-22}$ and one study found a higher overall mortality for patients diagnosed in late summer compared with those diagnosed in mid-winter. ${ }^{23}$

In Denmark, positioned at $55-58^{\circ}$ northern latitude, there is no sufficient sun to synthesise vitamin $\mathrm{D}$ in the human skin during 6-8 months of the year. Measurements of vitamin D in healthy Danish volunteers demonstrate a pronounced seasonal variation of vitamin $\mathrm{D}$ with a maximum in late summer and a minimum in early spring, which indicates that the content of vitamin D in the average Danish diet could not compensate for the lack of sun-induced vitamin $\mathrm{D}$ production during wintertime. ${ }^{24}$

If the vitamin $\mathrm{D}$ status at the time of the operation is important for the overall survival (OS), it should be both easy and inexpensive to adjust preoperatively. The aim of this study is to compare the prognostic outcome for early breast cancer patients diagnosed and operated at different seasons of the year based on a large population-based registration of women with breast cancer in 
Denmark including detailed information on prognostic factors.

\section{MATERIALS AND METHODS}

The Danish Breast Cancer Cooperative Group (DBCG) founded in 1977 is a population-based registry, which collects data on almost all cases of invasive breast cancer among residents in Denmark (a population of 5.5 million, emigration and immigration rates $<2 \%$ ) (http://www.dst.dk). Virtually, all involved Danish hospital departments have applied DBCG's guidelines for diagnostic procedures, surgery, radiotherapy, adjuvant systemic therapy and follow-up for early breast cancer. Diagnostic, therapeutic and follow-up data have been accumulated prospectively in the DBCG registry by the use of standardised forms. The DBCG Data Center applied the same procedures for all patients, including monitoring and analysis of data, whether or not the patients participated in randomised trials. ${ }^{25}$

\section{Cases}

The present analysis includes all women, who had a completely resected invasive carcinoma of the breast and no signs of distant metastasis as determined by routine examinations (physical examination, clinical chemistry, chest radiography and other examinations if indicated). Cases with bilateral breast cancer were included $(n=1535)$, and the tumour characteristics of the side with the least favourable prognostic impact were recorded in the DBCG registry. A negative sentinel node biopsy or axillary clearance (levels I and II) in combination with breast-conserving surgery or mastectomy was required. Radiotherapy to the breast was mandatory following lumpectomy. Further description of the database and treatment guidelines has been given elsewhere. ${ }^{25} 26$

From 1 June 1978 to 31 May 2010, 89409 cases were registered. Of these, 3113 had a diagnosis of previous breast cancer, other malignancy (except non-melanoma skin tumours) or distant metastasis and 610 patients were not operated. Further excluded from the analyses were patients with unknown tumour size $(n=2045)$ and/ or unknown axillary lymph node status $(n=5678)$. In total, 79658 cases were included for further analyses (figure 1).

\section{Variables}

The seasons of surgery, generally $1-3$ weeks after the diagnosis, were defined as follows: winter (1 December to 28 or 29 February), spring (1 March to 31 May), summer (1 June to 31 August) and autumn (1 September to 30 November), so the summer period includes the months with the possibility of most sun exposure due to the altitude of the sun and vacations. Treatment periods were categorised according to the national programmes initiated in 1977, 1982, 1989, 1999, 2001, 2004 and $2007 .^{25}$ The age at surgery was categorised in intervals: $\leq 39,40-49,50-59,60-69,70-79$

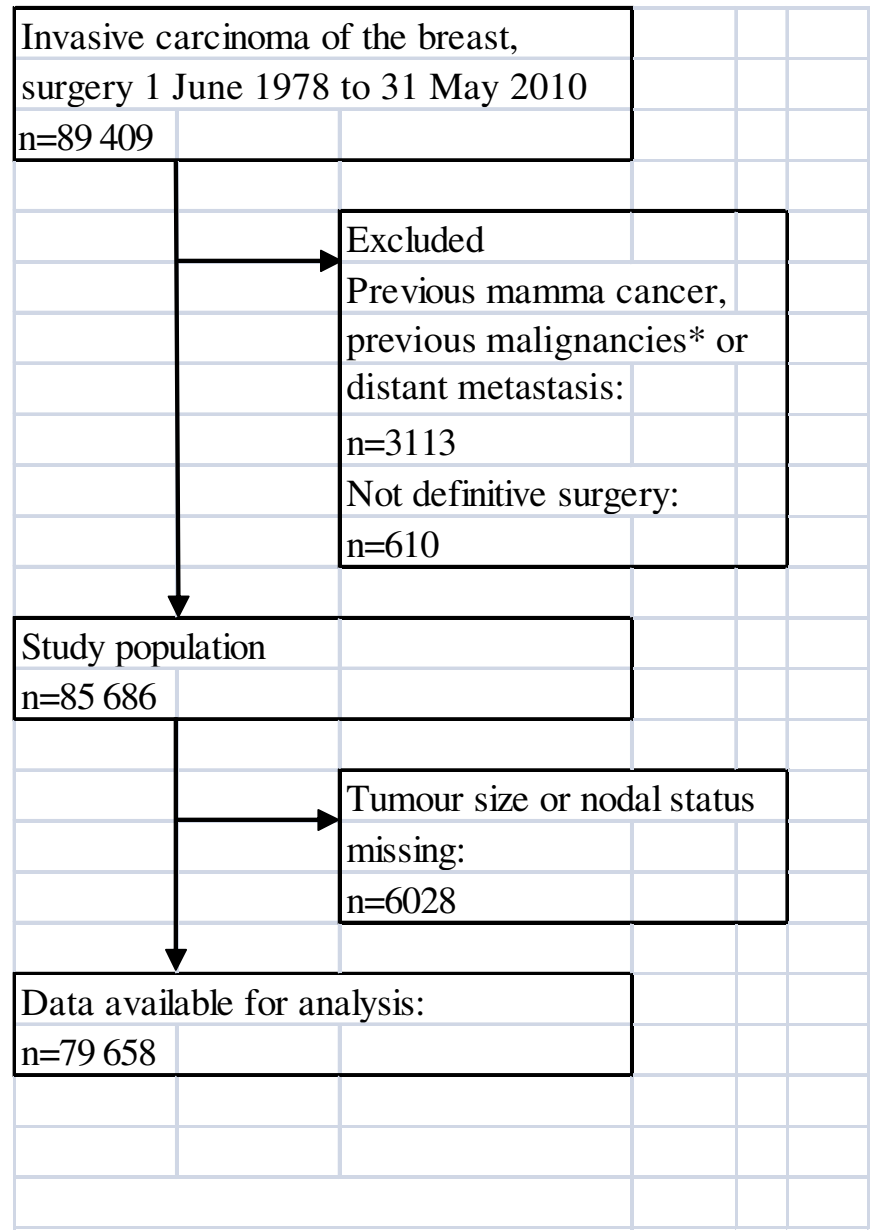

Figure 1 Flow diagram: prospective registration of Danish women operated for early breast cancer 1978-2010. *Except non-melanoma skin tumours.

and $\geq 80$ years. Tumour size was categorised according to the largest tumour diameter: $0-10,11-20,21-50$ and $\geq 51 \mathrm{~mm}$. The spread of breast cancer to locoregional lymph nodes was categorised as negative, one to three positive lymph nodes and four or more positive lymph nodes. The hormone receptor status was categorised as: negative, oestrogen receptor or progesterone receptor positive and unknown. The histopathological status was categorised in five groups as: grade I, II or III ductal carcinoma, lobular carcinoma and carcinoma of other types or unknown diagnosis. The frequency of allocated systemic treatment (chemotherapy and endocrine therapy) by season of surgery was reported.

\section{End point}

OS was measured from the date of surgery to the date of death. Observations were censored at emigration or at 1 June 2011, which was the date of data withdrawal of patient vital status from the Danish Centralised Civil Register.

\section{Statistical analysis}

The association between OS and season of surgery was analysed by Cox proportional hazards regression 
models. $^{27} 28$ The effects of season of surgery were analysed in models with an increasing level of adjustment for prognostic variables: models stratified by treatment programme (adjusted I); models stratified by treatment programme and age at surgery (adjusted II) and models stratified by treatment programme, age at surgery, hormone receptor status and lymph node status and further including the effects of tumour size and histological type (fully adjusted). The interpreta- tions of a seasonal effect on survival in these models differ according to the level of adjustment. In the fully adjusted model, the seasonal effect includes the effects of unknown or not included prognostic variables including the alleged effect of vitamin D. In the adjusted II model, the seasonal effect includes the effects of both known and unknown prognostic variables. In the adjusted I model, the seasonal effect further includes the effects of referral pattern, that is, patient age at

Table 1 Prognostic factors by season among 79658 Danish women operated for early breast cancer between 1 June 1978 and 31 May 2010

\begin{tabular}{|c|c|c|c|c|c|c|c|c|c|c|}
\hline \multirow[b]{2}{*}{ Characteristic } & \multicolumn{2}{|l|}{ Winter } & \multicolumn{2}{|l|}{ Spring } & \multicolumn{2}{|c|}{ Summer } & \multicolumn{2}{|c|}{ Autumn } & \multicolumn{2}{|l|}{ Total } \\
\hline & $\mathbf{n}$ & $\%$ & $n$ & $\%$ & $\mathbf{n}$ & $\%$ & $\mathbf{n}$ & $\%$ & $\mathbf{n}$ & $\%$ \\
\hline Total & 18760 & & 20067 & & 20033 & & 20798 & & 79658 & \\
\hline \multicolumn{11}{|l|}{ Age at surgery* } \\
\hline$\leq 39$ years & 1051 & 5.6 & 1057 & 5.3 & 1001 & 5.0 & 1094 & 5.3 & 4203 & 5.3 \\
\hline 40-49 years & 3249 & 17.3 & 3604 & 18.0 & 3524 & 17.6 & 3637 & 17.5 & 14014 & 17.6 \\
\hline $50-59$ years & 4906 & 26.2 & 5251 & 26.2 & 5232 & 26.1 & 5461 & 26.3 & 20850 & 26.2 \\
\hline $60-69$ years & 5203 & 27.7 & 5506 & 27.4 & 5520 & 27.6 & 5702 & 27.4 & 21931 & 27.5 \\
\hline $70-79$ years & 3233 & 17.2 & 3436 & 17.1 & 3541 & 17.7 & 3642 & 17.5 & 13852 & 17.4 \\
\hline$\geq 80$ years & 1118 & 6.0 & 1213 & 6.0 & 1215 & 6.1 & 1262 & 6.1 & 4808 & 6.0 \\
\hline \multicolumn{11}{|l|}{ Period of surgery } \\
\hline 1977-1989 & 4592 & 24.5 & 4783 & 23.8 & 5115 & 25.5 & 5448 & 26.2 & 19938 & 25.0 \\
\hline $1990-1999$ & 5626 & 30.0 & 6160 & 30.7 & 6359 & 31.7 & 6559 & 31.5 & 24704 & 31.0 \\
\hline 2000-2010 & 8542 & 45.5 & 9124 & 45.5 & 8559 & 42.7 & 8791 & 42.3 & 35016 & 44.0 \\
\hline \multicolumn{11}{|l|}{ Tumour size } \\
\hline $0-10 \mathrm{~mm}$ & 2832 & 15.1 & 3136 & 15.6 & 2972 & 14.8 & 3211 & 15.4 & 12151 & 15.3 \\
\hline $11-20 \mathrm{~mm}$ & 7419 & 39.5 & 7983 & 39.8 & 7945 & 39.7 & 8310 & 40.0 & 31657 & 39.7 \\
\hline $21-50 \mathrm{~mm}$ & 7469 & 39.8 & 7964 & 39.7 & 8053 & 40.2 & 8201 & 39.4 & 31687 & 39.8 \\
\hline$>50 \mathrm{~mm}$ & 1040 & 5.5 & 984 & 4.9 & 1063 & 5.3 & 1076 & 5.2 & 4163 & 5.2 \\
\hline \multicolumn{11}{|l|}{ Nodal status $\S$} \\
\hline Negative & 9767 & 52.1 & 10672 & 53.2 & 10723 & 53.5 & 11233 & 54.0 & 42395 & 53.2 \\
\hline $1-3$ positive & 5772 & 30.8 & 5984 & 29.8 & 5915 & 29.5 & 6015 & 28.9 & 23686 & 29.7 \\
\hline$\geq 4$ positive & 3221 & 17.2 & 3411 & 17.0 & 3395 & 16.9 & 3550 & 17.1 & 13577 & 17.0 \\
\hline \multicolumn{11}{|l|}{ Histological group } \\
\hline Ductal grade I & 4808 & 25.6 & 5129 & 25.6 & 5242 & 26.2 & 5390 & 25.9 & 20569 & 25.8 \\
\hline Ductal grade II/?** & 7268 & 38.7 & 7672 & 38.2 & 7542 & 37.6 & 7893 & 38.0 & 30375 & 38.1 \\
\hline Ductal grade III & 3351 & 17.9 & 3504 & 17.5 & 3517 & 17.6 & 3626 & 17.4 & 13998 & 17.6 \\
\hline Lobular & 1963 & 10.5 & 2135 & 10.6 & 2086 & 10.4 & 2137 & 10.3 & 8321 & 10.4 \\
\hline Other invasive & 1370 & 7.3 & 1627 & 8.1 & 1646 & 8.2 & 1752 & 8.4 & 6395 & 8.0 \\
\hline \multicolumn{11}{|l|}{ ER-PgR status } \\
\hline Negative & 2919 & 15.6 & 3176 & 15.8 & 3299 & 16.5 & 3217 & 15.5 & 12611 & 15.8 \\
\hline Positive & 12453 & 66.4 & 13054 & 65.1 & 12994 & 64.9 & 13849 & 66.6 & 52350 & 65.7 \\
\hline Unknown & 3388 & 18.1 & 3837 & 19.1 & 3740 & 18.7 & 3732 & 17.9 & 14697 & 18.5 \\
\hline $\begin{array}{l}\text { Per cent } \mathrm{Er}-\mathrm{PgR} \\
\text { positive } \dagger \neq \neq\end{array}$ & & 81.0 & & 80.4 & & 79.8 & & 81.1 & & 80.6 \\
\hline \multicolumn{11}{|c|}{ Adjuvant systemic therapy } \\
\hline None & 9449 & 50.4 & 10256 & 51.1 & 10551 & 52.7 & 10940 & 52.6 & 41196 & 51.7 \\
\hline Chemotherapy§§ & 4749 & 25.3 & 5063 & 25.2 & 4849 & 24.2 & 5043 & 24.2 & 19704 & 24.7 \\
\hline Endocrine therapy $₫ \mathbb{\Phi}$ & 6270 & 33.4 & 6629 & 33.0 & 6347 & 31.7 & 6654 & 32.0 & 25900 & 32.5 \\
\hline \multicolumn{11}{|c|}{ 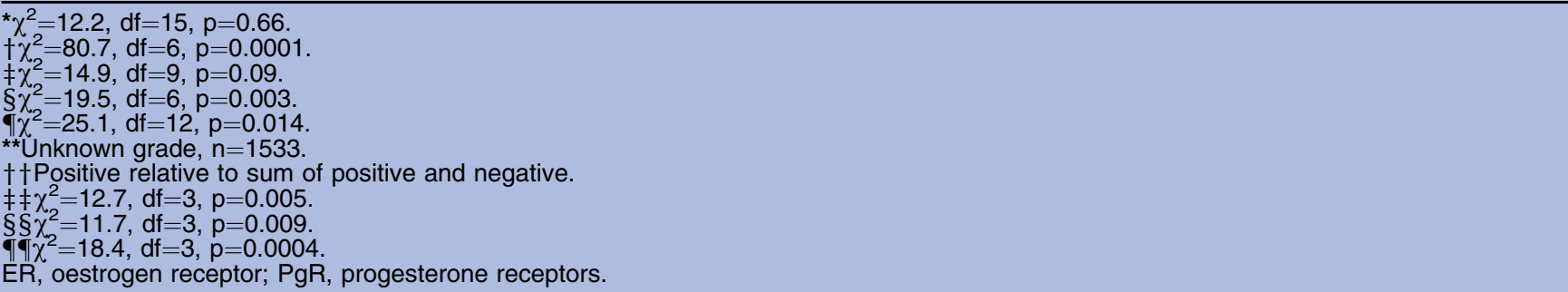 } \\
\hline
\end{tabular}


Table 2 Overall survival by Cox proportional hazards regression at survival periods $0-1,0-2,0-5$ and $0-10$ years post-surgery

\begin{tabular}{|c|c|c|c|c|c|c|}
\hline \multirow{2}{*}{$\begin{array}{l}\text { Period of follow-up } \\
\text { Season of surgery }\end{array}$} & \multicolumn{2}{|l|}{ Adjusted I* } & \multicolumn{2}{|l|}{ Adjusted II $†$} & \multicolumn{2}{|l|}{ Fully adjusted $\ddagger$} \\
\hline & HR $(95 \% \mathrm{Cl})$ & p Value & HR $(95 \% \mathrm{Cl})$ & p Value & HR $(95 \% \mathrm{Cl})$ & p Value \\
\hline \multicolumn{7}{|l|}{$0-1$ years after surgery } \\
\hline Winter & 1 (reference) & \multirow[t]{4}{*}{0.053} & 1 (reference) & \multirow[t]{4}{*}{0.067} & 1 (reference) & \multirow[t]{4}{*}{0.052} \\
\hline Spring & 1.07 (0.95 to 1.20$)$ & & $1.06(0.95$ to 1.19$)$ & & 1.07 (0.96 to 1.20$)$ & \\
\hline Summer & 1.09 (0.97 to 1.22$)$ & & $1.08(0.96$ to 1.21$)$ & & $1.12(1.00$ to 1.25$)$ & \\
\hline Autumn & $0.95(0.84$ to 1.06$)$ & & $0.94(0.84$ to 1.06$)$ & & 0.97 (0.86 to 1.09$)$ & \\
\hline \multicolumn{7}{|c|}{$0-2$ years after surgery } \\
\hline Winter & 1 (reference) & \multirow[t]{4}{*}{0.19} & 1 (reference) & \multirow[t]{4}{*}{0.17} & 1 (reference) & \multirow[t]{4}{*}{0.43} \\
\hline Spring & $0.99(0.92$ to 1.06$)$ & & $0.98(0.92$ to 1.06$)$ & & $1.00(0.93$ to 1.07$)$ & \\
\hline Summer & $0.99(0.92$ to 1.06$)$ & & 0.99 (0.92 to 1.06$)$ & & $1.01(0.94$ to 1.08$)$ & \\
\hline Autumn & $0.93(0.87$ to 1.00$)$ & & $0.93(0.86$ to 1.00$)$ & & $0.96(0.89$ to 1.03$)$ & \\
\hline \multicolumn{7}{|c|}{$0-5$ years after surgery } \\
\hline Winter & 1 (reference) & \multirow[t]{4}{*}{0.60} & 1 (reference) & \multirow[t]{4}{*}{0.48} & 1 (reference) & \multirow[t]{4}{*}{0.96} \\
\hline Spring & $0.98(0.94$ to 1.03$)$ & & $0.98(0.94$ to 1.03$)$ & & $1.00(0.95$ to 1.04$)$ & \\
\hline Summer & $0.98(0.94$ to 1.02$)$ & & 0.97 (0.93 to 1.02$)$ & & $1.00(0.95$ to 1.04$)$ & \\
\hline Autumn & $0.97(0.93$ to 1.01$)$ & & 0.97 (0.93 to 1.01$)$ & & 0.99 (0.95 to 1.03$)$ & \\
\hline \multicolumn{7}{|c|}{$0-10$ years after surgery } \\
\hline Winter & 1 (reference) & \multirow[t]{4}{*}{0.90} & 1 (reference) & \multirow[t]{4}{*}{0.81} & 1 (reference) & \multirow[t]{4}{*}{0.92} \\
\hline Spring & 1.00 (0.96 to 1.03$)$ & & $1.00(0.96$ to 1.03$)$ & & 1.01 (0.98 to 1.05$)$ & \\
\hline Summer & $1.00(0.96$ to 1.03$)$ & & 0.99 (0.96 to 1.03$)$ & & 1.01 (0.98 to 1.05$)$ & \\
\hline Autumn & 0.99 (0.95 to 1.02$)$ & & $0.98(0.95$ to 1.02$)$ & & $1.00(0.97$ to 1.04$)$ & \\
\hline
\end{tabular}

surgery. The stratification of the Cox models was chosen to meet the proportional hazards assumption as assessed by Schoenfeld residuals plots. ${ }^{27}$ The analyses were done for four survival periods: $0-1,0-2,0-5$ and $0-10$ years after surgery. The null hypothesis of no survival effect of season of surgery was assessed by the Wald $\chi^{2}$ statistic, and a two-sided $\mathrm{p}$ value $<0.05$ was considered statistically significant. The HRs of season of surgery (winter as reference level) together with their 95\% CIs are reported. Due to the long period of inclusion, the potential heterogeneity of seasonal effects according to period of inclusion was investigated in models including an interaction term of season of surgery and programme series (1977 and 1982 vs 1989 vs 1999, 2001, 2004 and 2007). Analysis was performed with SAS V.9.1 (SAS Institute).

\section{RESULTS}

The person-years of observation were 78587 for the survival period $0-1$ years, 151980 for the survival period $0-2$ years, 327646 for the survival period $0-5$ years and 516011 for the survival period $0-10$ years after surgery. For the latter group, the median observation period for patients without an event was 10.0 year. The basic characteristics of the patient material according to season of surgery are presented in table 1 .

HRs of OS up to 10 years with surgery performed in winter as reference are given in table 2. Overall, no statistically significant association between OS and season of surgery are observed in 2-, 5- and 10-year follow-up periods. Only for the 1-year follow-up, a close to significant association is observed $(p=0.052$, fully adjusted analysis); OS is highest for patients undergoing surgery in autumn (HR: $0.97,95 \%$ CI 0.86 to 1.09 ) and lowest for patients undergoing surgery in summer (HR: $1.12,95 \%$ CI 1.00 to 1.26 ). Heterogeneity of seasonal effects according to period of inclusion was not statistical significant irrespective of model adjustment or survival period.

\section{DISCUSSION}

In the present study, we found no evidence of a seasonal variation in the OS among almost 80000 Danish women with primary breast cancer. The strengths of this study are the sample size, the population-based approach in a limited geographic area, ${ }^{29}$ the prospectively collected characteristics of tumour and lymph node status and the long follow-up (median 10.0 years). The detailed information's offer the possibility of including season of surgery in a multivariate analysis with the variables year, age at surgery, tumour size, nodal status, hormone receptor status and histopathological type. It should be noted that in our analysis, the 'adjusted II' models are stratified by treatment programme and age at surgery only. Thus, the estimates of association between OS and seasonal of surgery are not affected by the variables 
potentially associated with vitamin $\mathrm{D}$ or season of surgery (tumour size, positive axillary nodes, high-grade tumours and oestrogen receptor/progesterone receptor status). Using this approach, the independent prognostic effect of season of surgery seems to disappear. The limitations of the study are the lack of information about serum vitamin $\mathrm{D}$ in the individual patient at the time of surgery. Using the estimated UV dose as surrogate for vitamin D status must cause reservation, as it is not known whether vitamin D status of the breast cancer patients follow that of the background population. Lack of seasonal variation in this study does not necessarily mean that vitamin $\mathrm{D}$ is not important for the OS for breast cancer patients. The serum vitamin D in Danish women treated for breast cancer could be so low even among patients treated in the summer-autumn so that no difference could be detected. One nested casecontrol study $(\mathrm{N}=142)$ showed lower serum vitamin D among Danish patients at the diagnostic mammography. ${ }^{14}$ Cross-sectional studies of the plasma vitamin D in healthy Danish volunteers demonstrate a higher level in summer-autumn than in winter-spring. ${ }^{24}$

Results from UK and Norway indicate a better prognosis if diagnosis of breast cancer takes place during the summer or autumn. ${ }^{20-22}$ This seasonal variation was interpreted as a result of vitamin D deficiency in the dark months of the year, although one author considered the possibility that the seasonal effect might be due to a relative higher rate of diagnoses in summer and the prevalence of infections during wintertime leading to early death. ${ }^{20}$ In contrast, results from Sweden demonstrate a worse OS for patients diagnosed in the summer probably due to a relative reduction in the number of early stage diagnoses from mammography screening which are closed in the summer months and the healthcare system treating primarily the most sick patients in holiday periods. ${ }^{23} 30$ Breast cancer is regarded as a relatively slow growing cancer, with a long preclinical course. ${ }^{31}$ If vitamin D level should be of etiologic or prognostic importance, it is supposed that the influence is working over a longer time period and not just reflected by vitamin $\mathrm{D}$ status at time of diagnosis. If the level of vitamin $\mathrm{D}$ at the time of surgery should influence prognosis, the mechanism must be differences in perioperative resistance to cancer dissemination and the logical precaution would be to ensure a high preoperative vitamin $\mathrm{D}$ level. However, limited evidence including the present study supports this statement.

Funding This research received no specific grant from any funding agency in the public, commercial or not-for-profit sectors.

Competing interests All authors have completed the ICMJE disclosure form (available on request from the corresponding author) and declare: no support from any organisation for the submitted work, no financial relationships with any organisations that might have an interest in the submitted work in the previous 3 years and no other relationships or activities that could appear to have influenced the submitted work.

Ethics approval The data are from Danish Breast Cancer Group.
Contributors DT contributed to conception and interpretation of data, reviewed the literature, drafted the article and finally approved the submitted paper. KDB analysed and interpreted the data, drafted the statistical part and finally approved the submitted paper. AMT and NK contributed to the interpretation of data, revised it critically for important intellectual contents and finally approved the submitted paper.

Provenance and peer review Not commissioned; externally peer reviewed.

\section{REFERENCES}

1. Kricker A, Armstrong B. Does sunlight have a beneficial influence on certain cancers? Prog Biophys Mol Biol 2006;92:132-9.

2. van der Rhee HJ, de Vries E, Coebergh JW. Does sunlight prevent cancer? A systematic review. Eur J Cancer 2006;42:2222-32.

3. Thorne J, Campbell MJ. The vitamin D receptor in cancer. Proc Nutr Soc 2008:67:115-27.

4. Welsh J. Vitamin D and prevention of breast cancer. Acta Pharmacol Sin 2007;28:1373-82.

5. Abbas S, Linseisen J, Slanger T, et al. Serum 25-hydroxyvitamin D and risk of post-menopausal breast cancer-results of a large case-control study. Carcinogenesis 2008;29:93-9.

6. Bertone-Johnson ER. Vitamin D and breast cancer. Ann Epidemiol 2009;19:462-7.

7. Chen P, Hu P, Xie D, et al. Meta-analysis of vitamin D, calcium and the prevention of breast cancer. Breast Cancer Res Treat 2010;121:469-77.

8. Crew KD, Gammon MD, Steck SE, et al. Association between plasma 25-hydroxyvitamin D and breast cancer risk. Cancer Prev Res (Phila Pa) 2009;2:598-604.

9. Garland CF, Garland FC, Gorham ED, et al. The role of vitamin D in cancer prevention. Am J Public Health 2006:96:252-61.

10. Goodwin PJ, Ennis M, Pritchard Kl, et al. Prognostic effects of 25-hydroxyvitamin D levels in early breast cancer. J Clin Oncol 2009;27:3757-63.

11. Kim HJ, Lee YM, Ko BS, et al. Vitamin D deficiency is correlated with poor outcomes in patients with luminal-type breast cancer. Ann Surg Oncol 2011;18:1830-6.

12. Palmieri C, MacGregor T, Girgis S, et al. Serum 25-hydroxyvitamin D levels in early and advanced breast cancer. $J$ Clin Pathol 2006;59:1334-6.

13. Perez-Lopez FR, Chedraui P, Haya J. Review article: vitamin D acquisition and breast cancer risk. Reprod Sci 2009;16:7-19.

14. Rejnmark L, Tietze A, Vestergaard $P$, et al. Reduced prediagnostic 25-hydroxyvitamin $D$ levels in women with breast cancer: a nested case-control study. Cancer Epidemiol Biomarkers Prev 2009;18:2655-60.

15. Vrieling A, Hein R, Abbas $S$, et al. Serum 25-hydroxyvitamin D and postmenopausal breast cancer survival: a prospective patient cohort study. Breast Cancer Res 2011;13:R74.

16. Chlebowski RT, Johnson KC, Kooperberg C, et al. Calcium plus vitamin $\mathrm{D}$ supplementation and the risk of breast cancer. $J$ Natl Cancer Inst 2008:100:1581-91.

17. Freedman DM, Chang SC, Falk RT, et al. Serum levels of vitamin D metabolites and breast cancer risk in the prostate, lung, colorectal, and ovarian cancer screening trial. Cancer Epidemiol Biomarkers Prev 2008;17:889-94.

18. Gandini S, Boniol M, Haukka J, et al. Meta-analysis of observational studies of serum 25-hydroxyvitamin D levels and colorectal, breast and prostate cancer and colorectal adenoma. Int $J$ Cancer 2011;128:1414-24.

19. Yin L, Grandi N, Raum E, et al. Meta-analysis: serum vitamin D and breast cancer risk. Eur J Cancer 2010;46:2196-205.

20. Lim HS, Roychoudhuri R, Peto J, et al. Cancer survival is dependent on season of diagnosis and sunlight exposure. Int $J$ Cancer 2006;119:1530-6.

21. Porojnicu AC, Lagunova Z, Robsahm TE, et al. Changes in risk of death from breast cancer with season and latitude: sun exposure and breast cancer survival in Norway. Breast Cancer Res Treat 2007; 102:323-8.

22. Robsahm TE, Tretli S, Dahlback A, et al. Vitamin D3 from sunlight may improve the prognosis of breast-, colon- and prostate cancer (Norway). Cancer Causes Control 2004;15:149-58.

23. Holmberg L, Adolfsson J, Mucci L, et al. Season of diagnosis and prognosis in breast and prostate cancer. Cancer Causes Control 2009;20:663-70.

24. Mosekilde L, Nielsen LR, Larsen ER, et al. [Vitamin D deficiency. Definition and prevalence in Denmark]. Ugeskr Laeger 2005; 167:29-33. 
25. Moller S, Jensen MB, Ejlertsen B, et al. The clinical database and the treatment guidelines of the Danish Breast Cancer Cooperative Group (DBCG); its 30-years experience and future promise. Acta Oncol 2008:47:506-24.

26. Ejlertsen B, Jensen MB, Rank F, et al. Population-based study of peritumoral lymphovascular invasion and outcome among patients with operable breast cancer. J Natl Cancer Inst 2009;101:729-35.

27. Schoenfeld D. Partial residuals for the proportional hazards regression model. Biometrika 2011;69:239-41.
28. Kalbfleisch JD, Prentice RL. The Statistical Analysis of Failure Time Data. John Wiley.

29. Kimlin MG. Geographic location and vitamin D synthesis. Mol Aspects Med 2008;29:453-61.

30. Lambe M, Blomqvist $P$, Bellocco R. Seasonal variation in the diagnosis of cancer: a study based on national cancer registration in Sweden. Br J Cancer 2003;88:1358-60.

31. Gullino PM. Natural history of breast cancer. Progression from hyperplasia to neoplasia as predicted by angiogenesis. Cancer 1977;39(6 Suppl):2697-703. 